\title{
A comparative study of bone mineral density in females doing weight bearing exercise and non-weight bearing exercise using dual energy $\mathrm{x}$-ray absorptiometry
}

\author{
Shilpa Gantela ${ }^{1, *}$, A. Hemalatha Devi \\ ${ }^{1}$ Assosicate Professor, ${ }^{2}$ Professor \& HOD, Dept. of Physiology, Katuri Medical College, Guntur, Andhra Pradesh, India
}

*Corresponding Author:

Email: shilpa.gantela@gmil.com

Received: $12^{\text {th }}$ February, 2018

Accepted: $22^{\text {nd }}$ February, 2018

\begin{abstract}
Osteoporosis is reported to effect 44 million adults, of whom $80 \%$ are women. Exercise appears to influence the osteogenic response and can lead to higher values of Bone mineral density. A minimum research is done on bone mineral density using dual energy x-ray absorptiometry (DEXA) in India. Weight bearing exercises seem to have a better effect than nonweight bearing exercises.

Aim: our aim of this retrospective cohort study is to confirm that weight bearing exercise is beneficial to bone mineral density than non weight bearing exercise.

Materials and Methods: A total of 50 healthy active women $(n=50)$ doing weight bearing exercises like tennis playing and gym weight workouts for atleast one hour, for 5 days a week were taken. (Group A). A total of 50 healthy walkers with minimum walking of one hour for 5 days a week were taken (Group B). Dual-energy X-ray absorptiometry (DXA) was done to assess the bone mineral density in all the participants. Bone mineral density (BMD) in gram per square centimeter of lumbar spine (L1-L4), surgical neck of right humerus and total body BMD was assessed with a hologic QDR-1000/W pencil-beam bone densitometer, using the spine scan mode. Statistical analysis was done using Statistical package for the social sciences (SPSS software, version 13.0). Analysis of covariance was used to determine whether there were significant differences between groups in bone mineral density, adusting height and weight.

Results: The Total body BMD in $\mathrm{gm} / \mathrm{cm} 2$ in group A is $1.172 \pm 0.034$ and the Total body BMD in $\mathrm{gm} / \mathrm{cm} 2$ in group B is 1.078 \pm 0.053. ( $\mathrm{P}$ value $<0.001$ ) Lumbar spine $\mathrm{BMD}$ in $\mathrm{gm} / \mathrm{cm} 2$ in Group $\mathrm{A}$ is $1.216 \pm 0.122$ and the Lumbar spine BMD in $\mathrm{gm} / \mathrm{cm} 2$ in Group B is $0.968+/-0.128$. ( $\mathrm{P}$ value $<0.05$ ) Humerus BMD in $\mathrm{gm} / \mathrm{cm} 2$ in group A is $1.22 \pm 0.043$ and the BMD in $\mathrm{gm} / \mathrm{cm} 2$ in group $\mathrm{B}$ is $1.110 \pm 0.066$. (P value $<0.001)$.

Conclusion: since, the Total body BMD, Lumbar spine BMD, Humerus BMD in $\mathrm{gm} / \mathrm{cm} 2$ is higher in subjects doing weight bearing exercise when compared to the subjects doing non weight bearing exercise. We confirm that weight bearing exercises are beneficial to bones when compared to nonweight bearing exercises.
\end{abstract}

Keywords: Bone mineral density, Dual energy x-ray absorptiometry, Osteoporosis.

\section{Introduction}

Bones $^{1}$ in human body have always been considered as only internal framework of the body, but they serve multiple functions like, attachment point for skeletal muscles, tendons and ligaments, haemopoiesis from bone marrow, reserves of minerals important for the body, mostly calcium and phosphorus, buffering the blood against excessive $\mathrm{pH}$ changes by absorbing or releasing alkaline salts. Bone cells also release a hormone called osteocalcin, which regulates blood sugar (glucose) and fat deposition. Osteocalcin increases the insulin secretion and sensitivity, and boosts the number of insulin-producing cells and reduces stores of fat.

Bones are imaged, using radiography like ultrasound X-ray, CT scan, MRI scan and dual energy X-ray absorptiometry (DEXA). Arthritis, infections, osteoporosis and tumours, can affect bone making it weak and vulnerable to fractures.

Osteoporosis $^{2}$ is a disease of bone where bone mineral density is reduced increasing the likelihood of fractures. Osteoporosis is defined in women by the World Health Organization as a bone mineral density of 2.5 standard deviations below peak bone mass, relative to the age and sex-matched average. Osteoporosis can effect both men and women of all ages. Treatment is to quit smoking, decrease alcohol consumption, exercise regularly, ${ }^{3}$ and have a healthy diet. Calcium supplements may also be advised, as may Vitamin D and medications like bisphosphonates, Strontium ranelate, and hormone replacement therapy.

Physical activity ${ }^{4}$ plays an important role in maintaining healthy bones. Especially weight bearing Physical activity stimulates the bones to remodel and to adapt their structure based on the load they are exposed to. According to previous research, athletes involved in weight bearing play or exercise, had higher bone mass densities, when compared to athletes involved in training which involved less weight bearing like swimming. Our study aims at measuring the bone mineral density in women doing weight bearing exercises and in women doing non weight bearing exercises. So that, a knowledge of this, might want the 
women to choose the form of exercise which would be beneficial for their bones.

The National Osteoporosis Foundation recommends a Bone Mineral Density test (BMD) using a central DEXA machine to diagnose osteoporosis. DEXA stands for dual energy x-ray absorptiometry. ${ }^{5}$

Dual-energy x-ray absorptiometry or DEXA, is an enhanced form of X-ray technology. It is commonly used to diagnose osteoporosis and to assess an individual's risk for developing fractures. DEXA is simple, quick and noninvasive. It uses a small dose of ionizing radiation to produce images of bones to measure bone loss.

\section{Materials and Methods}

\section{Subjects}

A total of 50 healthy active women $(n=50)$ doing weight bearing exercises like tennis playing and gym weight workouts for at least one hour, for 5 days a week were taken. (Group A)

A total of 50 healthy walkers with minimum walking of one hour for 5 days a week were taken.

(Group B)

\section{Exclusion criteria:}

All the subjects with pregnancies during study, menstrual irregularities, experience of fractures, surgeries, height limitations, weight limitations, eating disorders musculoskeletal disorders steroid abuse, smoking, alcoholism, diabetes mellitus or any other disease that could lead to osteopenia were excluded from the study.

\section{Inclusion criteria:}

All subjects who have been exercising for at least an year were taken in this study.
All participants gave written informed consent before the study.

Ethical committee and financial committee clearance was obtained from Katuri medical college and hospital.

Anthropometric measurements of height and weight were taken. Height was measured using standard tape measure on a wall. Weight was measured using standard electronic weighing machine.

\section{DEXA analysis}

Dual-energy X-ray absorptiometry (DXA) was done to assess the bone mineral density in all the participants. On the day of exam, the subjects were asked to eat normally. No calcium supplements were allowed before 24 hours of exam. The subjects were asked to wear loose clothing without any metal clips or ornaments on their bodies. Bone mineral density (BMD) in gram per square centimeter of lumbar spine (L1-L4), surgical neck of right humerus and total body BMD was assessed with a hologic QDR-1000/W pencil-beam bone densitometer, using the spine scan mode. Scans were performed by technicians and quality control was ensured.

\section{Statistical Analysis}

Statistical analysis was done using Statistical package for the social sciences (SPSS software, version 13.0). Analysis of covariance was used to determine whether there were significant differences between groups in bone mineral density, adjusting height and weight.

All data was presented as means and standard deviations. All $\mathrm{P}$ values were adjusted for multiple comparisons using Fischer's least significant difference method. $\mathrm{P}$ value $<0.05$ is considered significant.

\section{Results}

Table 1:

\begin{tabular}{|l|c|c|}
\hline & $\begin{array}{c}\text { N=50 subjects doing } \\
\text { weight bearing exercises } \\
\text { (Group A) }\end{array}$ & $\begin{array}{c}\text { N=50 subjects doing non } \\
\text { weight bearing exercises } \\
\text { (Group B) }\end{array}$ \\
\hline Age & $23 \pm 5.0$ & $22+/-6.2$ \\
\hline Height & $160.1 \pm 4.7$ & $158.2+/-6$ \\
\hline Weight & $61.1 \pm 8.2$ & $57.9+/-4$ \\
\hline
\end{tabular}

Table 2:

\begin{tabular}{|l|c|c|c|}
\hline & $\begin{array}{c}\text { BMD gm/cm2 } \\
\text { Weight bearing } \\
\text { exercise (Group A) }\end{array}$ & $\begin{array}{c}\text { BMD gm/cm2 } \\
\text { Non weight } \\
\text { bearing exercise } \\
\text { (Group B) }\end{array}$ & P value \\
\hline Total body & $1.172 \pm 0.034$ & $1.078+/-0.053$ & $<0.001$ \\
\hline $\begin{array}{l}\text { Lumbar } \\
\text { spine }\end{array}$ & $1.216 \pm 0.122$ & $0.968+/-0.128$ & $<0.05$ \\
\hline Humerus & $1.22 \pm 0.043$ & $1.110+/-0.066$ & $<0.001$ \\
\hline
\end{tabular}


Complete data were available on 100 females, of which $\mathrm{N}=50$ belong to group $\mathrm{A}$ which constitutes females doing weight bearing exercises and $\mathrm{N}=50$ belong to group $\mathrm{B}$ which constitutes females doing non weight bearing exercise.

Table 1 summarizes the anthropometric data per group. No significant differences were observed between subjects of both group A and group B regarding anthropometric data.

Table 2 summarizes the BMD in $\mathrm{gm} / \mathrm{cm} 2$ per group. A data printout from the DXA scan provided values for total-body BMD, lumbar spine BMD, humerus BMD for each participant. The total body $\mathrm{BMD}$ in $\mathrm{gm} / \mathrm{cm} 2$ in group $\mathrm{A}$ is $1.172 \pm 0.034$ and the Total body BMD in $\mathrm{gm} / \mathrm{cm} 2$ in group B is $1.078 \pm 0.053$. ( $\mathrm{P}$ value < 0.001) Lumbar spine BMD in $\mathrm{gm} / \mathrm{cm} 2$ in Group A is $1.216 \pm 0.122$ and the Lumbar spine BMD in $\mathrm{gm} / \mathrm{cm} 2$ in Group B is $0.968+/-0.128$. ( $\mathrm{P}$ value $<0.05$ ) humerus BMD in $\mathrm{gm} / \mathrm{cm} 2$ in group $\mathrm{A}$ is $1.22 \pm 0.043$ and the BMD in $\mathrm{gm} / \mathrm{cm} 2$ in group $\mathrm{B}$ is $1.110 \pm 0.066$. ( $\mathrm{P}$ value $<0.001)$. So, the total body BMD, Lumbar spine BMD, humerus BMD in $\mathrm{gm} / \mathrm{cm} 2$ is higher in subjects doing weight bearing exercise when compared to the subjects doing non weight bearing exercise.

\section{Discussion}

Mechanical factors ${ }^{6}$ because of their ability to influence growth, modeling and remodeling activities of bones can improve the quality of determinants of fracture resistance. But, the right kind of exercise, that can make a difference or help prevent or treat osteoporosis has been researched upon by many. ${ }^{7}$ Training programs stressing axial loads of the skeletal system have lead to an increase of BMD in the spine and the hip of young individuals. Extreme physical stress has modified the bone quality in young individuals. ${ }^{8}$

The study we have done is a retrospective cohort study, to compare the bone mineral density of subjects who do weight bearing exercises (Group A) like playing tennis, lifting weights while doing strengthening exercise in gyms and subjects who indulge in only non-weight bearing exercises (Group B), like swimming and walking only. Dual-energy Xray absorptiometry (DXA) was done to assess the bone mineral density in all the subjects. Total body BMD in $\mathrm{gm} / \mathrm{cm}_{2}$ in group $\mathrm{A}$ is $1.172 \pm 0.034$ is higher than the Total body BMD in $\mathrm{gm} / \mathrm{cm}^{2}$ in group B is $1.078 \pm 0.053$. ( $P$ value $<0.001$ ). These finding correlate well the research of Skerry, T. et al on their research on what sort of exercise is beneficial to the skeleton. ${ }^{9}$ Lumbar spine BMD in $\mathrm{gm} / \mathrm{cm}^{2}$ in Group A is $1.216 \pm 0.122$ is more than Lumbar spine BMD in $\mathrm{gm} / \mathrm{cm}^{2}$ in Group B is $0.968 \pm 0.128$. ( $\mathrm{P}$ value $<0.05$ ), this results agrees with Tommerup LJ Crenshaw TD, et al in their research on weight-bearing exercise affecting non-weight-bearing bone $^{10}$ humerus $\mathrm{BMD}$ in $\mathrm{gm} / \mathrm{cm} 2$ in group $\mathrm{A}$ is
$1.22 \pm 0.043 \mathrm{BMD}$ in $\mathrm{gm} / \mathrm{cm}^{2}$ is significantly more than group B humerus BMD of $1.110 \pm 0.066$. (P value $<0.001$ )our findings agree with the research of J. A. L. Calbet, J. S. Moysi, ${ }^{11}$ et al on Bone Mineral Content and Density in Professional Tennis Players

Bone remodeling occurs because of a balance between bone formation and bone resorption. In female bodies, oestrogens ${ }^{12}$ maintain this balance by causing calcium and phosphate retention, inhibiting the production of osteoclast and suppressing their activity, inhibiting the production of interleukin-1, granulocyte macrophage colony stimulating factor which promote proliferation of osteoclasts. There are estrogen receptors on osteoblasts. ${ }^{13}$ So, a direct stimulating effect of oestrogen on them is a possibility. Loss of estrogens during menopause might cause more bone resorption, causing osteoporosis. So, along with weight bearing exercise, hormone replacement therapy would give additive effects on bone mineral density in premenopausal and post menopausal women.

The process of bone remodeling is one example of coordinated function of the endocrine and immune systems. The hormones involved in bone formation are growth hormone, insulin like growth factor, testosterone, oestrogen, transforming growth factor beta, skeletal growth factor, bone derived growth factor, calcitonin. Cytokines like interleukin-1 and interleukin6 play an important role in bone resorption. Bone adjusts its strength in proportion to the degree of bone stress. ${ }^{14}$ Shape of the bone can be rearranged for proper support of mechanical force in accordance with the stress. The development of new bone matrix maintains the toughness of bone.

Research has also identified that marathon runners ${ }^{15,16}$ have less BMD than Gymnasts and swimmers ${ }^{17}$ have less BMD than runners. So, inspite of the active lifestyle, the form of physical activity we choose, decide the morphology and strength of bones of human skeleton.

In summary, is walking enough as a perfect physical activity is questionable Weight-bearing physical activity causes new bone tissue to form, and this makes bones stronger. So, regular participation in weight bearing activities like lifting weights while doing strengthening exercises, playing tennis, dancing, stair climbing, doing high impact aerobics is also essential for bone mineral density and bone structure so that women can make better choices for a healthy future.

\section{References}

1. Steele, D. Gentry; Claud A. Bramblett (1988). The Anatomy and Biology of the Human Skeleton. Texas A\&M University Press. p.4

2. Seeman, E. Osteoporosis: trials and tribulations. Am. J. Med.103:74S-89S,1997. 
3. Swezey, R. L. Exercise for osteoporosis: is walking enough? The case for site specificity and resistive exercise. Spine 21:2809-13,1996.

4. Chilibeck, P., G. Digby, and C. Webber. Exercise and bone mineral density. Sports Med. 19:103-22, 1995.

5. Mazess RB, Chesnut CH, McClung M, Genant H (1992) Enhanced precision with dual-energy X-ray absorptiometry. Calcif Tissue Int 51:14-7.

6. Forwood, M. R. Mechanical effects on the skeleton: are there clinical implications? Osteoporos. Int.12:77-83, 2001.

7. American College of Sports Medicine. American College of Sports Medicine position stand: osteoporosis and exercise. Med. Sci. Sports Exerc. 27: i-vii, 1995.

8. Sabo D, Reiter A, Pfeil J, Gussbacher A, Niethard FU (1996)Modification of bone quality by extreme physical stress. Bonedensity measurements in high-performance athletes using dual-energy $\mathrm{x}$-ray absorptiometry. Z Orthop Ihre Grenzgeb 134:1-6.

9. Skerry, T. Mechanical loading and bone: what sort of exercise is beneficial to the skeleton. Bone 20:179-81, 1997.

10. Tommerup LJ, Raab DM, Crenshaw TD, Smith EL (1993) Does weight-bearing exercise affect non-weightbearing bone? J Bone Miner Res 8:1053-105.

11. J. A. L. Calbet,J. S. Moysi, C. Dorado, L. P. Rodrı'guez Bone Mineral Content and Density in Professional Tennis Players Calcif Tissue Int (1998) 62:491-6.

12. Korht, W., D. Snead, E. Slatopolsky, S. Birge, Additive Effects of Weight-Bearing Exercise and Estrogen on Bone Mineral Density in Older Women, Journal of Bone and Mineral Research, Volume 10:1303-11,1995.

13. Damien, E., J. Price, and L. Lanyon. The estrogen receptor's involvement in osteoblasts' adaptive response to mechanical strain. J. Bone Miner. Res. 13:1275-82, 1998.

14. Peterson SE, Peterson MD, Raymond G, Gilligan C, Checovich M (1991) Muscular strength and bone density with weight training in middle aged women. Med Sci Sports Exerc 23:499-504.

15. 23. Robinson TL, Snow-Harter C, Taaffe DR, Gillis D, Shaw J, Marcus R. Gymnasts exhibit higher bone mass than runners despite similar prevalence of amenorrhea and oligomenorrhea. J Bone Miner Res. 1995;10:26-35.

16. Frost $\mathrm{H}$. Why do marathon runners have less bone than weight lifters? A vital biomechanical view and explanation. Bone 199720183-9.

17. Taaffe DR, Snow-Harter C, Connolly DA, Robinson TL, Brown MD, Marcus R. Differential effects of swimming versus weight-bearing activity on bone mineral status of eumenorrheic athletes. J Bone Miner Res. 1995;10:58693. 